\title{
Functional Results after First- and Second-Generation Temporary Implantable Nitinol Device (TIND) for BPH: A Narrative Review of the Literature
}

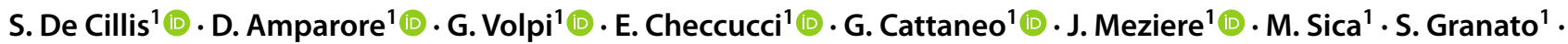 \\ P. Verri ${ }^{1} \cdot$ M. Manfredi ${ }^{1}$ (D) C. Fiori ${ }^{1}$ (D) F. Porpiglia ${ }^{1}$
}

Accepted: 4 January 2022 / Published online: 27 January 2022

(c) The Author(s) 2022

\begin{abstract}
Purpose of review In the last decades, new promising technologies for the treatment of BPH-related lower urinary tract symptoms (LUTS) have been widely experienced in clinical practice, with the aim of offering fewer complications but similar functional outcomes compared with the gold standard transurethral resection of the prostate (TURP). Among these so-called minimally invasive approaches, transurethral implantation of first- and second-generation temporary implantable nitinol device (TIND and iTIND, respectively) (Medi-Tate; Medi-Tate Ltd., Or Akiva, Israel) has been included by the European Association of Urology (EAU) Guidelines as one of the available alternative treatments to TURP. In the present paper, we conducted a systematic review of the current literature on TIND and iTIND implantation focusing on functional outcomes. Medline, Embase, and Cochrane databases were queried for relevant Literature in May 2021.

Recent findings Data regarding the use of temporary implantable nitinol device for BPH are still very limited, with only seven studies currently available in Literature. All the studies report that both TIND and iTIND procedures are safe, effective, and well tolerated. Moreover, such treatments seem to not affect patient's sexual and ejaculatory functions.

Summary Current clinical evidence suggests that temporary implantation of first- and second-generation temporary implantable nitinol devices are valid options for the minimally invasive surgical treatment of BPH-related LUTS. Further studies are required in order to confirm the functional results, especially over a long-term follow up.
\end{abstract}

Keywords TIND $\cdot$ BPH $\cdot$ Minimally invasive techniques $\cdot$ LUTS $\cdot$ Urethral implantable device $\cdot$ Nitinol

\section{Introduction}

Benign prostatic hyperplasia (BPH) associated with lower urinary tract symptoms (LUTS) is a very common condition affecting men above age of 50 years, reaching a prevalence over $80 \%$ in men above age of 70 years [1].

S. De Cillis and D. Amparore These authors contributed equally to the first manuscript.

This article is part of the Topical Collection on BPH-Related Voiding Dysfunction

S. De Cillis

Sabrinatitti.decillis@gmail.com

1 Department of Oncology, Division of Urology, School of Medicine, University of Turin, San Luigi Hospital, Orbassano (Turin), Italy
Suffering from severe LUTS is often referred as a very bothering condition that can cause to sleep disorders, low quality of life (QoL) [2], and potentially leading to complication from BPH [3]. Multiple treatment options can be offered to these patients to improve their QoL. Notwithstanding the prescription of lifestyle changes and oral medications (alpha-inhibitors, 5 alpha reductase inhibitors, phosphodiesterase 5 inhibitors, or combination) is currently the most chosen strategy to treat BPH associated LUTS [4], it is often insufficient to determine symptom relief and is not devoid of bothering side effects (sexual dysfunction, antegrade ejaculation, postural hypotension etc.) [5]. For these reasons, a fair proportion of these patients with BPH-related LUTS are in need to be treated surgically.

Transurethral resection of the prostate (TURP) is currently the gold standard endoscopic treatment for BPH [6], reaching impressive long-term results on International Prostatic Symptoms Score (IPSS) and on the increase of maximum urinary flow rate (Qmax) up to $-70 \%$ and $162 \%$, respectively [7]. 
However, clinicians and patients must keep in mind that TURP is commonly associated with perioperative and late postoperative complications (e.g., bleeding, urinary retention, retrograde ejaculation, bladder neck contractures) [7-9] that can represent conditions even more bothersome than severe LUTS.

In the last decades, various other surgical options have been proposed in clinical practice with the aim to minimize the risk of surgical complications in comparison with standard techniques, while producing a symptom's relief higher than oral medications. Endoscopic techniques such as laser enucleation, photo-vaporization, and water ablation of the prostate have demonstrated great efficacy, but have been shown to have not negligible rates of complications [9-16]. On the other hand, MIS does not seem to be burdened by a significant rate of AEs compared to TURP [17-20]. Among the increasing minimally invasive approaches investigated in literature, the European Association of Urology (EAU) guidelines cite steam injection (REZUM), prostatic artery embolization (PAE), prostatic injections, prostatic urethral lift (PUL), and the temporary implantable nitinol device (iTIND) as alternative treatments for BPH [6].

In the present work, we aim to report the most recent literature evidences inherent on the first- (TIND) and secondgeneration temporary implantable nitinol device (iTIND) in terms of short- and long-term postoperative functional outcomes, complications, and treatment failure rate.

\section{Device Characteristics Description}

The first-generation device is a 50-mm-long urethral stent composed of four nitinol struts and an anchoring leaflet. For safety reasons, the tip of the device is covered by plastic to avoid bladder injuries, while the tail is attached to a nylon wire for the device retrieval. Today, the first-generation device is out of commerce.

The second-generation device maintains the same size of the first-generation one with a main difference represented by the presence of only three struts configured in a tulip shape (Fig. 1). The struts are connected together at the cranial end, enhancing their action on the urethral mucosa and preventing injuries to the bladder, thanks to the absence of a pointy tip.

The device reaches an outer diameter of $33 \mathrm{~mm}$ allowing the struts to exert a circumferential force on the prostatic urethral mucosa, producing pressure-induced ischemic necrosis and consequent prostatic incisions at 12,5, and 7 o'clock position. These incisions are made gradually as the struts expand, with a progressive decrease in bladder neck tension.

\section{Implantation and Retrieval Technique}

The iTIND is implanted through a rigid cystoscope, under light sedation. The device is loaded into a 14-Fr system that can be positioned into the cystoscope sheath. Once in

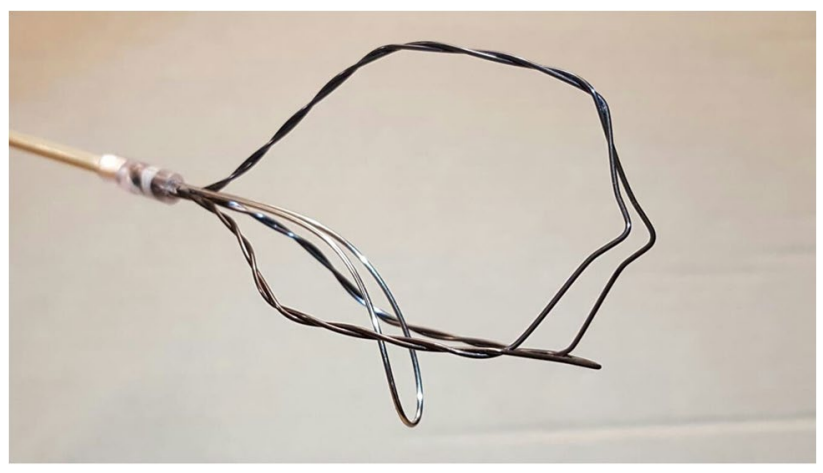

Fig. 1 iTIND. The device is composed of three struts made of a double intertwined nitinol wire conformed in a tulip shape and an anchoring leaflet. Its tail is composed of a nylon wire allowing its retrieval

the bladder, the device can be delivered and pulled at the level of bladder neck under direct vision (Fig. 2a). The struts of the device must be placed at 12, 5, and 7 o'clock and the leaflet should be located caudally to the bladder neck, but beyond the veru montanum (Fig. 2b). At the end of the procedure, the bladder is emptied to avoid urinary retention.

The device needs to remain in situ for 5 days after the implantation to exert its function. The retrieval can be performed with the use of a rigid cystoscope and light anesthesia, or alternatively through an open-ended catheter using a semi-rigid wire that catches the nylon wire of the device allowing to pull the iTIND into the catheter. The catheter is inserted along the urethra and the wire concomitantly pulled. Once the tail of the device is reached by the catheter, the traction of the wire allows its retrieval into the catheter lumen. The catheter is then removed. The procedures of implantation and retrieval are the same for TIND, but are described with the iTIND, being the firstgeneration device currently out of commerce.

\section{Evidence Acquisition}

Systematic research of the literature related to the implant of TIND or iTIND was conducted through Medline, Embase, and Cochrane databases in May 2021. In accordance with Preferred Reporting Items for Systematic Reviews and Meta-Analysis criteria (http:// www.prisma-statement.org) (Fig. 3), the selection of the studies followed the $\mathrm{PI}(\mathrm{C}) \mathrm{O}$ (Patient-Intervention-Comparison-Outcome) criteria. All studies including patients with BPH-related LUTS $(\mathrm{P})$ who underwent TIND implantation (I) and assessed for perioperative 
Fig. 2 iTIND placement: the device is delivered into the bladder and pulled toward the bladder neck under direct visualization (a). For the correct orientation of the device, its leaflet should be placed at 6 o'clock position, under the bladder neck but cranially to the veru montanum $(\mathbf{b})$

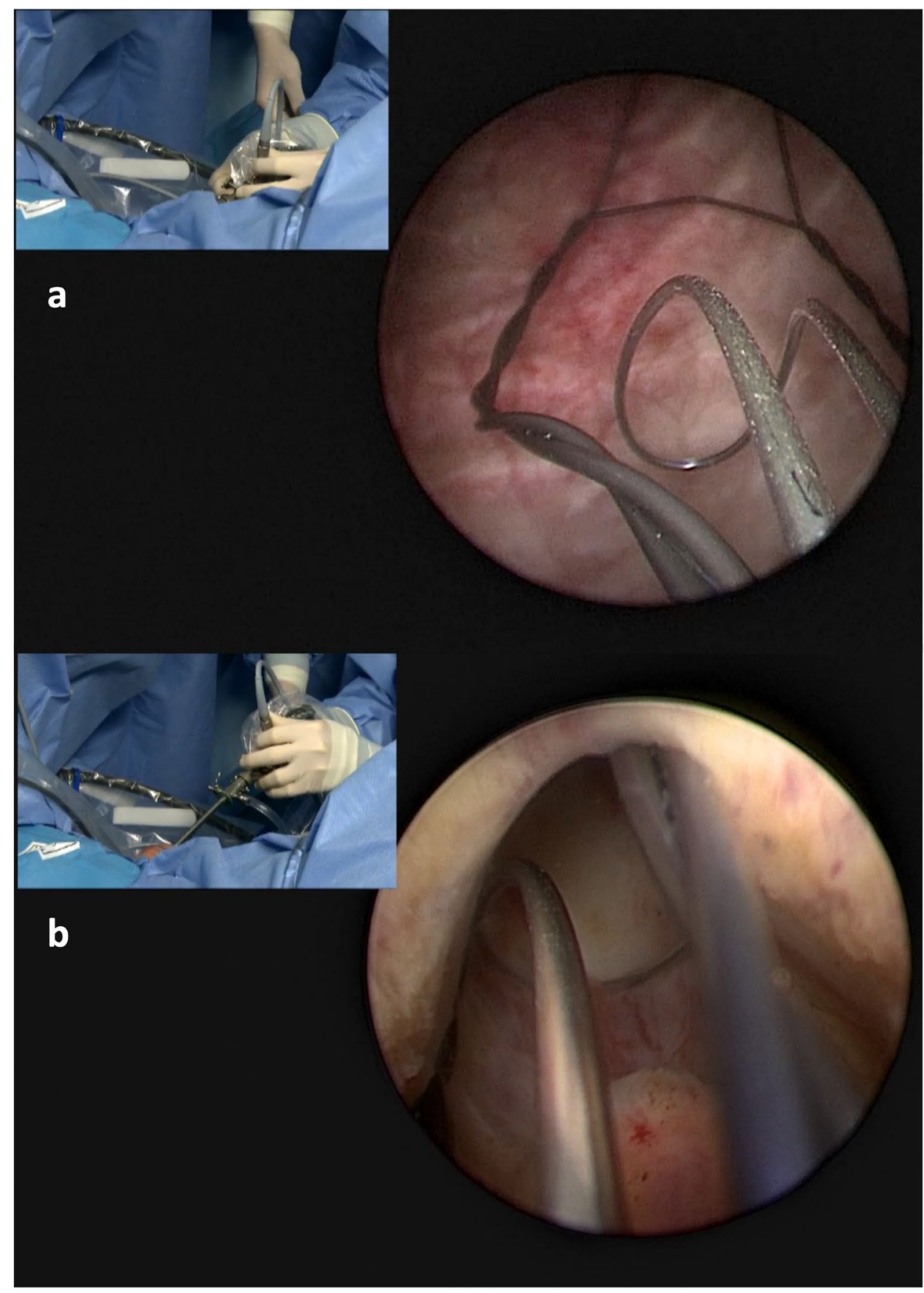

and long-term functional outcomes $(\mathrm{O})$ were considered eligible.

Two authors (SD and DA) reviewed the search results. Only English-language original articles were considered for the review. As a first step, title and abstracts were screened for eligibility. Exclusion criteria were non-primary data available (letters to the editor, case reports, commentaries, and reviews were considered ineligible) and non-English-language papers.

Second, a full-text analysis was performed on the remaining articles to confirm the inclusion.

\section{Evidence Synthesis}

The systematic research strategy identified a total of 2014 papers. After removal of duplicates, titles and abstract were screened for eligibility. Of these, eight publications were identified for full-text review, and ultimately seven studies were found to meet the inclusion criteria and selected for the narrative synthesis.

Given the presence in the literature of trials investigating the implantation of two different generations of temporary 
Fig. 3 PRISMA flow

Identification of studies via databases and registers

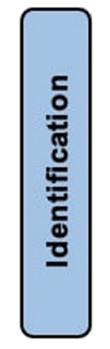

Records identified from Medline, Embase, and Cochrane databases: 2014
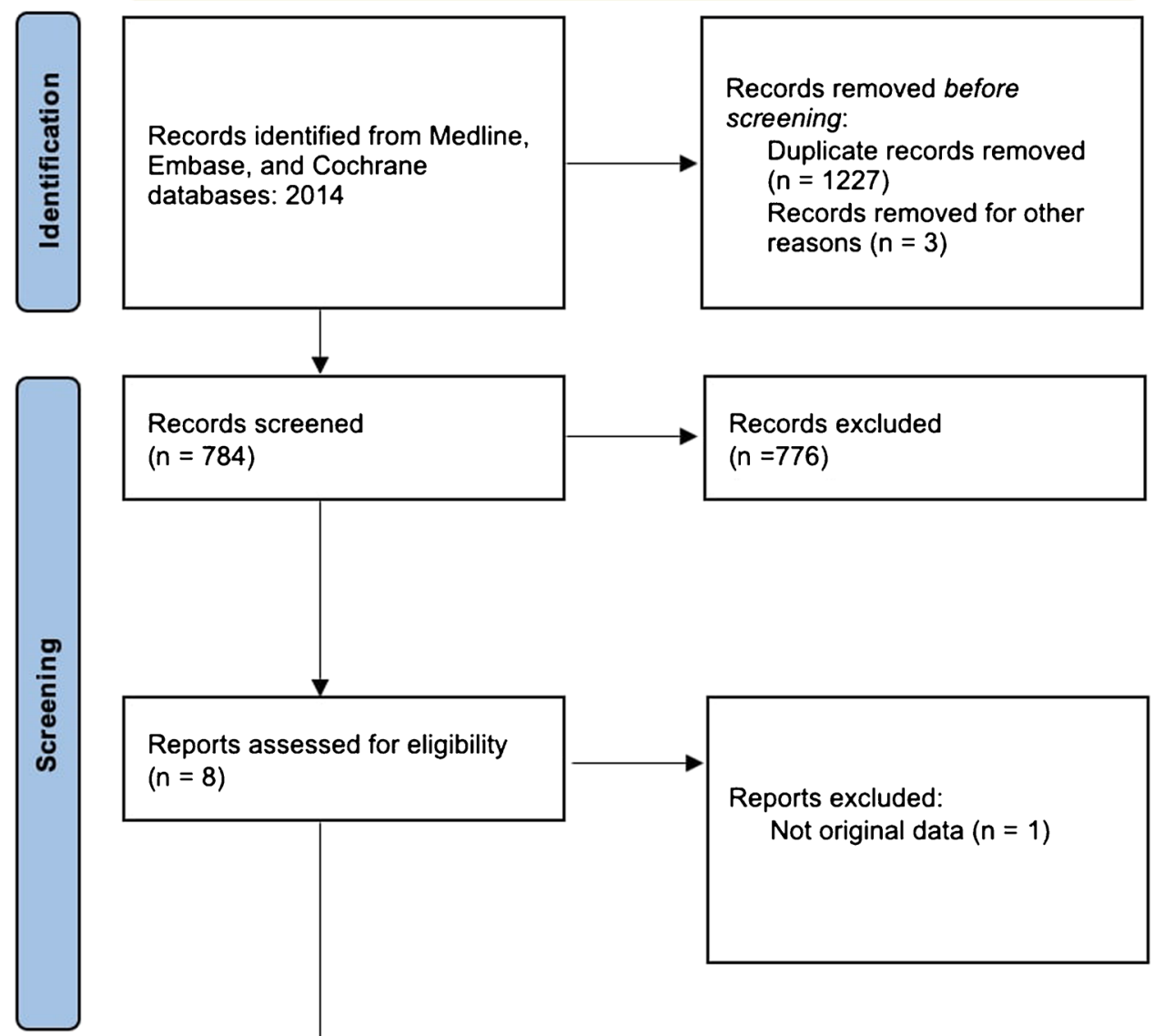

nitinol device, as illustrated previously, the narrative review will be addressed by dividing the available literature relevant to each device into sub-chapters.

\section{TIND}

To date, two articles have been published with the aim to investigate the safety and efficacy of the first-generation device, one being the report of the extended 3-year followup of the first series.

The first clinical trial on the implantation of TIND in men suffering from BPH-related LUTS (MT01 study) was conducted by Porpiglia et al. and published in 2015 [21].
In this prospective, single-center, single-arm study, 32 patients with age $>50$ years, International Prostate Symptom Score (IPSS) $\geq 10$, maximum peak urinary flow $(\mathrm{Qmax}) \leq 12 \mathrm{ml} / \mathrm{s}$, and a prostate volume assessed by transrectal ultra sound (TRUS) as $<60 \mathrm{ml}$ were included. All the devices were successfully implanted under light sedation with no intraoperative complications, and mean operative time was $5.8 \mathrm{~min}$. Authors underlined that the procedure was technically simple to perform and did not require any particular equipment.

All the patients were discharged within $24 \mathrm{~h}$ from the procedure, with only one patient unable to void spontaneously (Clavien-Dindo II) and requiring catheterization with a $10-\mathrm{F}$ Tiemann catheter. Aside from this case, three 
other patients experienced postoperative complications: one patient reported urinary incontinence 1 day after surgery (Clavien-Dindo III), and two patients developed urinary tract infections (UTIs) (Clavien-Dindo II).

All but one of the devices were removed on the fifth day after implantation in an outpatient setting via open-ended catheter. The retrievals were performed without complications and were well tolerated from the patients.

No postoperative ejaculation disorders were recorded among the 19 patients who were preoperative sexually active.

Concerning the efficacy of the treatment on the functional outcomes, the authors reported statistically significant improvement in postoperative IPSS and Qmax if compared with preoperative values.

Median IPSS dropped from 19 at baseline to 9 after 12 months (improvement of 45\%), while the mean Qmax raised from 7.6 to $11.9 \mathrm{ml} / \mathrm{s}$ (improvement of $67 \%$ ). Even Median IPSS QoL improved from 3 at baseline to 1 at 1 -year follow up. Such effect of the procedure on patient's quality of life was endorsed from the results of EPIC question 32 ("Overall, how satisfied are you with treatment you received for your prostate disease intervention?"), with $82 \%$ of the patients declaring that they were "satisfied" or "extremely satisfied" with the intervention. Indeed, in this series, no patient required further medical or surgical intervention to treat BPHrelated LUTS up to 1-year post-implantation follow-up.

With the aim to corroborate their previous encouraging findings, the same group published in 2018 the 3-year follow-up of the same cohort of the first trial [22].

The authors showed a significant change from baseline in IPSS, IPSS QoL score, and Qmax at every follow-up time point. In fact, at 36-month follow-up, the recorded Qmax value was $41 \%$ above baseline, median IPSS was 12 (6-24), and median IPSS QoL was $2(1-4)$.

Only three patients $(9 \%)$ required to resume their BPH medical therapy between 24 and 36 months after the procedure, while no further surgical interventions were needed to treat BPH-related LUTS in the study period.

The previous results on patient's quality of life, satisfaction, and ejaculatory function were confirmed even in the medium-term follow-up.

In terms of safety, aside from the early complications reported in the first work, no late complications were recorded during the 3 years after surgery.

\section{iTIND}

As described previously, the iTIND is the second-generation device and the only device today available on the market. For this reason, the literature concerning the implantation of iTIND could result more relevant in terms of current clinical practice.
With this systematic review, five articles evaluating the use of iTIND in men with LUTS have been found: three of them reporting the results of the same study cohort (MT02 study) at three different follow up time points, one reporting the shortterm results of the MT 06 study, and lastly, one paper reporting the outcomes of a randomized controlled trial.

The MT02 is a prospective, multicenter, single-arm trial investigating the feasibility, safety, and efficacy of iTIND implantation. Unlike the MT01 study, the inclusion criteria allowed the recruitment of patient with age $<50$ years and patients with Marion's disease. Moreover, all the included patients discontinued their medical therapy for BPH before the implant of iTIND ( 4 weeks and/or 6 months before the procedure in case of alpha-blockers or 5-ARIs, respectively). Obstructive median lobe, previous prostatic surgery, confounding bladder or sphincter dysfunction, active urinary infection, and antithrombotic or antiplatelet treatment were exclusion criteria.

The first short-term results of this trial have been published by Porpiglia et al. in 2019 [23]. In total, 81 patients were enrolled in 9 European and non-European urologic centers, with a mean age of 65 years, prostate volume of $40.5 \mathrm{ml}$, Qmax $7.3 \mathrm{ml} / \mathrm{s}$, IPSS 22.5, and a median IPSS QoL score of 4.

The implantation procedures were all uneventful. All the patients were discharged the same day of the surgery, and all the devices were retrieved a mean of 5.9 days after the implantation. The authors recorded only Clavien-Dindo Grade I or II complication, namely: hematuria (12.3\%), micturition urgency $(11.1 \%)$, pain $(9.9 \%)$, dysuria $(7.4 \%)$, UTIs $(6.2 \%)$, and urinary retention $(9.9 \%)$.

The treatment failure rate, defined as need of further medical or surgical intervention after iTIND implantation, for this trial was 5\% (two patients required TURP, two patients required combination therapy with alpha-blockers and 5-alpha-reductase inhibitor). Moreover, $12.3 \%$ of the patients were lost to follow-up, while 67 patients completed the 12-month follow-up.

In terms of functional outcomes, the authors recorded an improvement in Qmax, IPSS, and IPSS-QoL score at every time point. Mean Qmax reached $14.7 \mathrm{ml} / \mathrm{s}$ at the 12 -month follow-up visit, with an improvement of $+100 \%$ from baseline while mean IPSS dropped to 8.8 (improvement of 60\%). At the same time, the mean IPSS-QoL score decreased up to 1.6 by the end of the study. Moreover, as previously demonstrated for TIND, the implantation of iTIND did not cause any sexual or ejaculatory dysfunction in the sexually active patients of the cohort that completed 1-year follow-up.

To assess the durability of these findings, two more studies have been published in 2020 reporting the 2-year and 3 -year follow-up results of the MT02 study.

Kadner et al. [24] reported the outcomes of 51 patients who completed the 2-year follow-up. The improvement in 
functional aspects from baseline was shown to be significant at all time intervals up to 2 years after the procedure. IPSS urinary symptoms were reduced by 12 points at the end of the follow-up period. The symptomatic relief after the procedure was assessed by IPSS QoL Score with patients reporting a mean reduction of 2.4 points from baseline. The mean Qmax recorded an average increase of $8.38 \mathrm{ml} / \mathrm{s}$, reaching mean values of $16 \mathrm{ml} / \mathrm{s}$ at 24 months of follow-up. No sexual or ejaculation disorders were recorded.

Between 12 and 24 months, five patients experienced a treatment failure and underwent TURP. Of them, four patients were found to have a median prostatic lobe, although this should have been an exclusion criterion.

Data of the 3-year follow-up were available for 50 patients. For these patients, Amparore et al. [25•] demonstrated that the efficacy of the iTIND implantation remained stable up to 36 months. The authors reported average IPSS, QoL, Qmax, and post-voiding residual (PVR) of 8.55, 1.76, $15.2 \mathrm{ml} / \mathrm{s}$, and $9.38 \mathrm{ml}$ at the end of the study, improved from baseline by $-58.2,-55.6,+114.7$, and $-85.4 \%(p<0.0001)$. No late complications and no further surgical interventions were recorded between 24 and 36 months.

More recently, De Nunzio et al. [26] published an interim report of the first 70 patients enrolled in the MT06 study. It is a single-arm, prospective study conducted among urologic centers in Italy and Spain. The inclusion and exclusion criteria were the same as in the previous MT02 study, but unlike the latter, enrolled patients did not discontinue medical therapy before the intervention. This was the first iTIND study to use, in addition to IPSS, IPSS-QoL score, and EPIC 32 question, validated questionnaires to assess patients sexual (Sexual Health Inventory for Men questionnaire (SHIM)) and ejaculatory functions (Male Sexual Health Questionnaire (MSHQ-EjD)) together with continence state (Incontinence Symptom Index questionnaire (ISI)).

All the 70 procedures were successful, with no intraoperative complications. Device retrieval was performed with an average recorded VAS score of 3.4.

The only grade III complication reported was a gross hematuria presented few days after the iTIND retrieval in a patient with $80 \mathrm{~g}$ prostate. In this case, an endoscopic fulguration was required.

At 6-month follow-up, the authors noticed significant improvement in IPSS, IPSS QoL, and Qmax, reaching changes from baseline of $-12.7,-2.2$, and $4.6 \mathrm{ml} / \mathrm{s}$, respectively. No significant changes in PVR were recorded. Erectile and ejaculatory function as well as continence were preserved in all 70 patients, and even improved according to MSHQ-EjD questionnaire.

To date, the only available data of a comparative experience with the implant of iTIND were published in 2020

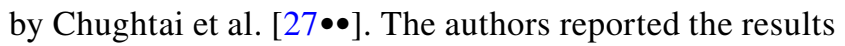
of a prospective, randomized, controlled, single-blinded study (MT03 study) conducted to compare the implant of iTIND to sham procedure for the treatment of BPHrelated LUTS. The study was conducted in 16 centers in Canada and USA and included patients with $\geq 50$ years, IPSS of $\geq 10$, Qmax of $\leq 12 \mathrm{ml} / \mathrm{s}$ with a $125 \mathrm{ml}$ voided volume, prostate volume between 25 and $75 \mathrm{cc}$, and normal blood and urine analysis. Exclusion criteria were similar to the previous studies. Notably, patients with obstructive median lobe, PSA $>10 \mathrm{ng} / \mathrm{ml}$ without a negative biopsy, and PVR $>250 \mathrm{ml}$ were considered not eligible. All the patients taking medications for BPH were invited to discontinue the treatment prior to the procedure (1 month for alpha-blockers and 6 months for 5-alpha-reductase inhibitors).

Subjects were randomized in 2:1 ratio to either iTIND or control. The iTIND implantation and retrieval were conducted with the previously described technique. For the sham procedure, the insertion and removal of a Foley 18 catheter was performed to simulate the implantation and retrieval of iTIND.

Overall, 185 patients were enrolled in this trial, being 128 treated with iTIND implantation and 57 assigned to sham control. The authors recorded mostly mild (Clavien-Dindo I or II) and transient adverse events, with an incidence of $38.1 \%$ in the iTIND arm in comparison with $17.5 \%$ in the control arm. In addition, $68 \%$ of the complications occurred within 7 days of treatment (before the device retrieval) and were in most part dysuria (22.9\% in iTIND group vs. $8.8 \%$ in sham group) and hematuria (13.6\% in iTIND group vs. $0 \%$ in sham group). No sexual or ejaculatory dysfunction were recorded.

In terms of efficacy, $78.9 \%$ of patients in iTIND group achieved an improvement of IPSS $>3$ points from baseline versus $60 \%$ of patients in the control arm at 3 months.

According to the SHIM and International Index of Erectile Function questionnaire, sexual function did not change. At 12 months, the iTIND group reported a mean decrease in IPSS of $9.25(P<0.0001)$, a $3.52 \mathrm{ml} / \mathrm{s}$ increase in peak urinary flow rate $(P<0.0001)$, and a 1.9 -point reduction in quality of life $(P<0.0001)$.

Overall, six patients required further surgical procedures while six patients required medical therapy for LUTS during the 1-year follow-up.

Table 1 reports the functional data (IPSS, IPSS QoL, Qmax) of the studies available in literature assessing the efficacy of iTIND.

\section{Discussion}

In the last decades, we have witnessed a large expansion of research in the field of treatments for BPH-related LUTS. Driven by the desire to offer the patient a resolution of 
Table 1 Functional outcomes after iTIND implantation

\begin{tabular}{|c|c|c|c|c|c|c|}
\hline & 1 month & 3 months & 6 months & 12 months & 24 months & 36 months \\
\hline \multicolumn{7}{|c|}{ Amparore et al., 2020} \\
\hline \multicolumn{7}{|l|}{ IPSS } \\
\hline$N$ & 78 & 75 & 70 & 67 & 51 & 50 \\
\hline Baseline & $22.22 \pm 5.62$ & $22.41 \pm 5.72$ & $21.99 \pm 5.48$ & $21.70 \pm 5.56$ & $20.51 \pm 4.58$ & $20.69 \pm 4.58$ \\
\hline Follow-up & $11.72 \pm 7.99$ & $9.77 \pm 6.69$ & $9.75 \pm 7.10$ & $8.78 \pm 6.41$ & $8.51 \pm 5.51$ & $8.55 \pm 6.38$ \\
\hline Change & $-10.50 \pm 8.32$ & $-12.63 \pm 7.40$ & $-12.23 \pm 6.79$ & $-12.92 \pm 6.92$ & $-12.00 \pm 6.12$ & $-12.14 \pm 6.95$ \\
\hline$\%$ change & $-46.3 \pm 33.2$ & $-55.0 \pm 29.3$ & $-56.4 \pm 27.5$ & $-59.1 \pm 26.3$ & $-56.7 \pm 25.6$ & $-58.2 \pm 32.1$ \\
\hline$(95 \% \mathrm{CI})$ & $(-54.0 \%,-38.5 \%)$ & $(-61.9 \%,-48.1 \%)$ & $(-63.0 \%,-49.8 \%)$ & $(-65.7 \%,-52.5 \%)$ & $(-64.1 \%,-49.4 \%)$ & $(-67.4 \%,-49.0 \%)$ \\
\hline$P$ value & $<0.0001$ & $<0.0001$ & $<0.0001$ & $<0.0001$ & $<0.0001$ & $<0.0001$ \\
\hline \multicolumn{7}{|l|}{ IPSS QoL } \\
\hline$N$ & 78 & 75 & 70 & 67 & 51 & 50 \\
\hline Baseline & $4.00 \pm 0.84$ & $3.97 \pm 0.84$ & $3.97 \pm 0.84$ & $3.97 \pm 0.87$ & $3.96 \pm 0.87$ & $3.96 \pm 0.87$ \\
\hline Follow-up & $2.08 \pm 1.35$ & $1.83 \pm 1.30$ & $1.81 \pm 1.30$ & $1.59 \pm 1.29$ & $1.76 \pm 1.32$ & $1.76 \pm 1.32$ \\
\hline Change & $-1.92 \pm 1.50$ & $-2.14 \pm 1.48$ & $-2.16 \pm 1.44$ & $-2.38 \pm 1.60$ & $-2.20 \pm 1.46$ & $-2.20 \pm 1.46$ \\
\hline$\%$ change & $-45.8 \pm 34.4$ & $-51.7 \pm 34.9$ & $-53.3 \pm 32.5$ & $-56.9 \pm 38.5$ & $-54.0 \pm 38.5$ & $-55.6 \pm 37.0$ \\
\hline$(95 \% \mathrm{CI})$ & $(-53.8 \%,-37.8 \%)$ & $(-59.9 \%,-43.5 \%)$ & $(-61.1 \%,-45.5 \%)$ & $(-66.5 \%,-47.3 \%)$ & $(-64.8 \%,-43.2 \%)$ & $(-66.2 \%,-45.0 \%)$ \\
\hline$P$ value & $<0.0001$ & $<0.0001$ & $<0.0001$ & $<0.0001$ & $<0.0001$ & $<0.0001$ \\
\hline \multicolumn{7}{|l|}{ Qmax } \\
\hline$N$ & 78 & 75 & 70 & 67 & 51 & 50 \\
\hline Baseline & $7.28 \pm 2.49$ & $7.44 \pm 2.43$ & $7.58 \pm 2.43$ & $7.61 \pm 2.25$ & $7.62 \pm 2.25$ & $7.71 \pm 2.26$ \\
\hline Follow-up & $11.23 \pm 5.66$ & $12.40 \pm 7.52$ & $13.69 \pm 6.26$ & $14.91 \pm 8.06$ & $16.00 \pm 7.43$ & $15.20 \pm 6.59$ \\
\hline Change & $3.94 \pm 5.22$ & $4.96 \pm 6.96$ & $6.12 \pm 6.22$ & $7.30 \pm 8.20$ & $8.38 \pm 7.93$ & $7.49 \pm 6.86$ \\
\hline$\%$ change & $79.4 \pm 167.7$ & $75.4 \pm 105.2$ & $95.6 \pm 106.5$ & $111.7 \pm 147.1$ & $130.8 \pm 132.2$ & $114.7 \pm 108.5$ \\
\hline$(95 \% \mathrm{CI})$ & $(41.1 \%, 117.7 \%)$ & $(50.7 \%, 100.1 \%)$ & $(70.1 \%, 121.2 \%)$ & $(74.3 \%, 149.0 \%)$ & $(93.3 \%, 168.4 \%)$ & $(83.2 \%, 146.2 \%)$ \\
\hline$P$ value & $<0.0001$ & $<0.0001$ & $<0.0001$ & $<0.0001$ & $<0.0001$ & $<0.0001$ \\
\hline \multicolumn{7}{|c|}{ De Nunzio et al., 2020} \\
\hline \multicolumn{7}{|c|}{ IPSS } \\
\hline$N$ & 70 & 70 & 70 & - & - & - \\
\hline Baseline & $21.2 \pm 6.0$ & $21.2 \pm 6.0$ & $21.2 \pm 6.0$ & - & - & - \\
\hline Follow-up & $9.5 \pm 6.8$ & $7.8 \pm 5.4$ & $8.3 \pm 6.7$ & - & - & - \\
\hline Change & $-11.7 \pm 8.3$ & $-13.4 \pm 6.4$ & $-12.7 \pm 6.9$ & - & - & - \\
\hline$\%$ change & - & - & - & - & - & - \\
\hline$(95 \% \mathrm{CI})$ & - & - & - & - & - & - \\
\hline$P$ value & $<0.01$ & $<0.01$ & $<0.01$ & - & - & - \\
\hline \multicolumn{7}{|l|}{ IPSS QoL } \\
\hline$N$ & 70 & 70 & 70 & - & - & - \\
\hline Baseline & $4.1 \pm 1.0$ & $4.1 \pm 1.0$ & $4.1 \pm 1.0$ & - & - & - \\
\hline Follow-up & $1.8 \pm 1.4$ & $1.6 \pm 1.3$ & $2.0 \pm 1.4$ & - & - & - \\
\hline Change & $-2.4 \pm 1.5$ & $-2.5 \pm 1.6$ & $-2.2 \pm 1.6$ & - & - & - \\
\hline$\%$ change & - & - & - & - & - & - \\
\hline$(95 \% \mathrm{CI})$ & - & - & - & - & - & - \\
\hline$P$ value & $<0.01$ & $<0.01$ & $<0.01$ & - & - & - \\
\hline \multicolumn{7}{|l|}{ Qmax } \\
\hline$N$ & 70 & 70 & 70 & - & - & - \\
\hline Baseline & $7.3 \pm 2.2$ & $7.3 \pm 2.2$ & $7.3 \pm 2.2$ & - & - & - \\
\hline Follow-up & $13.2 \pm 5.5$ & $11.8 \pm 5.1$ & $12.0 \pm 5.4$ & - & - & - \\
\hline Change & $5.8 \pm 5.5$ & $4.5 \pm 5.2$ & $4.6 \pm 5.5$ & - & - & - \\
\hline$\%$ change & - & - & - & - & - & - \\
\hline$(95 \% \mathrm{CI})$ & - & - & - & - & - & - \\
\hline$P$ value & $<0.01$ & $<0.01$ & $<0.01$ & - & - & - \\
\hline
\end{tabular}


Table 1 (continued)

\begin{tabular}{|c|c|c|c|c|c|c|}
\hline & 1 month & 3 months & 6 months & 12 months & 24 months & 36 months \\
\hline \multicolumn{7}{|c|}{ Chughtai et al., 2020} \\
\hline \multicolumn{7}{|l|}{ IPSS } \\
\hline$N$ & 96 & 80 & - & 78 & - & - \\
\hline Baseline & $22.37 \pm 6.92$ & $22.38 \pm 6.84$ & - & $21.64 \pm 6.80$ & - & - \\
\hline Follow-up & $12.80 \pm 7.40$ & $12.57 \pm 6.95$ & - & $12.69 \pm 6.35$ & - & - \\
\hline Change & $-9.57 \pm 8.29$ & $-9.48 \pm 8.49$ & - & $-9.25 \pm 6.49$ & - & - \\
\hline$\%$ change & - & - & - & - & - & - \\
\hline$(95 \% \mathrm{CI})$ & $(-11.3$ to -7.9$)$ & $(-11.4$ to -7.6$)$ & - & $(-11.0$ to -7.4$)$ & - & - \\
\hline$P$ value & $<0.0001$ & $<0.0001$ & - & $<0.0001$ & - & - \\
\hline \multicolumn{7}{|l|}{ IPSS QoL } \\
\hline$N$ & 96 & 80 & - & 78 & - & - \\
\hline Baseline & $4.66 \pm 1.31$ & $4.55 \pm 1.27$ & - & $4.51 \pm 1.24$ & - & - \\
\hline Follow-up & $2.83 \pm 1.88$ & $2.54 \pm 1.82$ & - & $2.45 \pm 1.79$ & - & - \\
\hline Change & $-1.83 \pm 1.97$ & $-1.96 \pm 1.86$ & - & $-1.90 \pm 1.74$ & - & - \\
\hline$\%$ change & - & - & - & - & - & - \\
\hline$(95 \% \mathrm{CI})$ & $(-2.2$ to -1.4$)$ & $(-2.3$ to -1.4$)$ & - & $(-2.2$ to -1.4$)$ & - & - \\
\hline$P$ value & $<0.0001$ & $<0.0001$ & - & $<0.0001$ & - & - \\
\hline \multicolumn{7}{|l|}{ Qmax } \\
\hline$N$ & 73 & 65 & - & 55 & - & - \\
\hline Baseline & $8.01 \pm 2.21$ & $8.63 \pm 2.71$ & - & $8.42 \pm 2.09$ & - & - \\
\hline Follow-up & $13.33 \pm 10.50$ & $13.55 \pm 6.40$ & - & $11.93 \pm 4.89$ & - & - \\
\hline Change & $5.32 \pm 10.33$ & $5.01 \pm 6.39$ & - & $3.52 \pm 5.24$ & - & - \\
\hline$\%$ change & - & - & - & - & - & - \\
\hline$(95 \% \mathrm{CI})$ & (2.9 to 7.7 ) & (3.4 to 6.6 ) & - & (2.0 to 5.0$)$ & - & - \\
\hline$P$ value & $<0.0001$ & $<0.0001$ & - & $<0.0001$ & - & - \\
\hline
\end{tabular}

IPSS International Prostate Symptoms Score, IPSS QoL International Prostate Symptoms Score Quality of Life, Qmax peak urinary flow, PVR post-void residual

symptoms comparable to the surgical gold standard TURP while exposing them to a lower risk of side effects, urologists have provided several alternative surgical techniques over the years. Laser enucleation, photovaporization, and water ablation of the prostate are widely used endoscopic techniques, but they have been shown to produce non-negligible complication rates [10-15]. For this reason, in recent years the scientific community has turned its interest more toward the so-called minimally invasive techniques, including iTIND. This study aimed to perform a narrative review of the available literature about TIND implantation in terms of functional results, complications, and treatment failure rate.

Focusing on the procedure from a perioperative management perspective, iTIND implantation turns out to be a lowcost, low-impact procedure. All available studies state that the implant procedure is technically easy to perform, can be carried out with the patient under light sedation, and has a short operative time (average $5.8 \mathrm{~min}$ for MT02 study) [22]. Patients without complications can be discharged the same day of surgery without the need for catheterization. These are great advantages for both physicians and patients, but it must be kept in mind that the device must remain in situ for an average of 4.3-5.7 days, being a possible cause discomfort $[26,27 \bullet \bullet]$. That said, it has been proven that the level of pain during the implantation period gradually decreases over time, and even during the removal procedure it settles on VAS score range of 3.3-3.4 [22, 26, 27••]. Return to normal activity after device removal averages 4.3-5.5 days [26].

Regarding complications, the data available in the literature on iTIND implantation are heterogeneous. In the MT02 study, $9.9 \%$ of urinary retentions treated by catheterization were reported [25•]. However, this report is not in line with the remaining available literature, which reports a ClavienDindo III complication rate ranging from 1.4 to $2.3 \%$, characterizing the iTIND implant as a safe procedure for the treatment of BPH-related LUTS [22-24, 26, 27••]. In the population treated in the available trials, only one patient required reoperation because of gross hematuria [19]. Moreover, the procedure appears to be safe at least up to 3 years 
after implantation, according to the longest follow-up studies available [23, 25•].

Concerning functional outcomes, TIND has been shown to result in significant improvements in terms of IPSS, IPSS QoL, and Qmax. These improvements are recorded from the first month post-surgery and improved subsequently reaching a peak at 24 months [26]. At 3 years of followup, IPSS, IPSS QoL, and Qmax improved by - 58.2, - 55.6, and +114.7 compared to baseline, respectively [25•]. The data regarding the decrease in PVR are heterogeneous, not always demonstrating a statistically significant decrease compared to preoperative data. Sexual and ejaculatory functions are never compromised after such "minimally invasive treatment," making this procedure very interesting for the growing segment of patients willing to preserve these functions [22-24, 25•, 26, 27••]. Nevertheless, it must be specified that the evaluation of these outcomes is not performed in a standardized or comparable way in all studies. In fact, only two of the available studies performed these evaluations using validated questionnaires $[26,27 \bullet \bullet]$.

In terms of treatment failure (intended as the need of medical or surgical retreatment), iTIND demonstrated 3-year surgical rate of $8.6 \%$ [25•]. This rate is acceptable when compared with that of TURP, which shows similar rates in literature [28]. That said, studies with longer follow-up and randomized controlled trials are needed to assess the longterm efficacy of TIND implantation and consequently have a more accurate account of surgical retreatment rates. In the next few months, a prospective, multi-center, 1:1 randomized trial (MT08) will start the recruitment, aiming to compare the safety of iTIND implantation versus TURP. Certainly, the data of the MT08 study will help to clarify the role of this minimally invasive technique for the treatment of BPH-related LUTS.

\section{Conclusions}

Data regarding the use of temporary implantable nitinol device for BPH are still limited: only five studies have been published regarding the iTIND, the second generation of this device and the only one currently available on the market.

Only one randomized controlled trial has been published, showing promising results in terms of safety, tolerability, and efficacy when compared with sham procedure, up to 12 months of follow-up. Concerning functional results, all the studies available report both an improvement in BPHrelated symptoms and peak urinary flow, as well as preservation of sexual and ejaculatory functions.

Additional studies are necessary to determine the durability of these results over a longer period of time since only short- and mid-term follow-up have been published yet. A prospective, randomized controlled trial comparing safety of
iTIND versus TURP will start in the next months in Europe and the USA.

\section{Declarations}

Conflict of Interest S. De Cillis, D. Amparore, G. Volpi, E. Checcucci, G. Cattaneo, J. Meziere, M. Sica, S. Granato, P. Verri, M. Manfredi, C. Fiori, and F. Porpiglia declare that they have no conflict of interest.

Open Access This article is licensed under a Creative Commons Attribution 4.0 International License, which permits use, sharing, adaptation, distribution and reproduction in any medium or format, as long as you give appropriate credit to the original author(s) and the source, provide a link to the Creative Commons licence, and indicate if changes were made. The images or other third party material in this article are included in the article's Creative Commons licence, unless indicated otherwise in a credit line to the material. If material is not included in the article's Creative Commons licence and your intended use is not permitted by statutory regulation or exceeds the permitted use, you will need to obtain permission directly from the copyright holder. To view a copy of this licence, visit http://creativecommons.org/licenses/by/4.0/.

\section{References}

Papers of particular interest, published recently, have been highlighted as:

- Of importance

$\bullet$ Of major importance

1. Egan KB. The epidemiology of benign prostatic hyperplasia associated with lower urinary tract symptoms: prevalence and incident rates. Urol Clin North Am. 2016;43(3):289-97. https:// doi.org/10.1016/j.ucl.2016.04.001.

2. Pinto JD, He HG, Chan SW, Wang W. Health-related quality of life and psychological well-being in men with benign prostatic hyperplasia: an integrative review. Jpn J Nurs Sci. 2016;13(3):309-23. https://doi.org/10.1111/jjns.12115.

3. Anderson JB, Roehrborn CG, Schalken JA, Emberton M. The progression of benign prostatic hyperplasia: examining the evidence and determining the risk. Eur Urol. 2001;39(4):3909. https://doi.org/10.1159/000052475.

4. Sun Y, Peng B, Lei GL, Wei Q, Yang L. Study of phosphodiesterase 5 inhibitors and $\alpha$-adrenoceptor antagonists used alone or in combination for the treatment of lower urinary tract symptoms due to benign prostatic hyperplasia. Minerva Urol Nefrol. 2020;72(1):13-21. https://doi.org/10.23736/S03932249.19.03408-8

5. Leow JJ, Cindolo L, Pirozzi L, Fanizza C, Romero M, Tubaro A, Autorino R, De Nunzio C, Schips L. Drug adherence and clinical outcomes for patients under pharmacological therapy for lower urinary tract symptoms related to benign prostatic hyperplasia: population-based cohort study. Eur Urol. 2015;68(3):418-25. https://doi.org/10.1016/j.eururo.2014.11.006.

6. Gravas S, Cornu JN, Gacci M, C. Gratzke, Herrmann TRW, Mamoulakis C, Rieken M, Speakman MJ, Tikknen KAO. EAU Guidelines on the management of non-neurogenic male LUTS. Edn. presented at the EAU Annual Congress Milan 2021. ISBN 978-94-92671-13-4 
7. Cornu JN, Ahyai S, Bachmann A, de la Rosette J, Gilling P, Gratzke C, McVary K, Novara G, Woo H, Madersbacher S. A systematic review and meta-analysis of functional outcomes and complications following transurethral procedures for lower urinary tract symptoms resulting from benign prostatic obstruction: an update. Eur Urol. 2015;67(6):1066-96. https://doi.org/ 10.1016/j.eururo.2014.06.017.

8. Rassweiler J, Teber D, Kuntz R, Hofmann R. Complications of transurethral resection of the prostate (TURP) - incidence, management, and prevention. Eur Urol. 2006 Nov;50(5):969-79; discussion 980. doi: https://doi.org/10.1016/j.eururo.2005.12.042.

9. Cacciamani GE, Cuhna F, Tafuri A, Shakir A, Cocci A, Gill K, Gómez Rivas J, Dourado A, Veneziano D, Okhunov Z, Capogrosso P, Hueber PA, Alberseen M, Abreu A, Migliorini F, Fiori C, Porcaro AB, Porpiglia F, Desai M, Russo GI; European Association of Urology Young Academic Urologists (EAU-YAU) Urotechnology and Men's Health working groups. Anterograde ejaculation preservation after endoscopic treatments in patients with bladder outlet obstruction: systematic review and pooledanalysis of randomized clinical trials. Minerva Urol Nefrol. 2019;71(5):427-434. doi: https://doi.org/10.23736/S0393-2249. 19.03588-4.

10. Tuccio A, Sessa F, Campi R, et al. En-bloc endoscopic enucleation of the prostate: a systematic review of the literature. Minerva Urol Nefrol. 2020;72(3):292-312. https://doi.org/10. 23736/S0393-2249.20.03706-6.

11. Rapisarda S, Russo GI, Osman NI, Chapple CR, Morgia G, Tubaro A, Esperto F; EAU-ESRU (European Associations of Urology-European Society of Residents Urologist). The use of laser as a therapeutic modality as compared to TURP for the small prostate $\leq 40 \mathrm{~mL}$ : a collaborative review. Minerva Urol Nefrol. 2019;71(6):569-575. doi: https://doi.org/10.23736/ S0393-2249.19.03350-2.

12. Kim KH, Kim SW, Son HS, Kim DK, Jung DC, Kim HW, Kim JC, Hong SJ, Kim JH. Role of Holmium laser enucleation of the prostate to increase cancer detection rate in patients with grayzone PSA level. Minerva Urol Nefrol. 2019;71(1):72-8. https:// doi.org/10.23736/S0393-2249.18.03186-7.

13. Rai P, Srivastava A, Singh S, Dhayal IR. Comparison of bipolar plasmakinetic transurethral enucleation and resection of prostate gland in patients receiving anticoagulants and/or platelet aggregation inhibitors. Minerva Urol Nefrol. 2019;71(3):286-93. https://doi.org/10.23736/S0393-2249.19.03282-X (Epub 2019 Jan 28 PMID: 30700082).

14. Reale G, Marchioni M, Altieri V, Greco F, De Nunzio C, Destefanis P, Ricciardulli S, Bergamaschi F, Fasolis G, Varvello F, Voce S, Palmieri F, Divan C, Malossini G, Oriti R, Tuccio A, Ruggera L, Tubaro A, Delicato G, Laganà A, Dadone C, De Rienzo G, Ditonno A, Frattini A, Pucci L, Carrino M, Montefiore F, Germani S, Miano R, Schips L, Rabito S, Ferrari G, Cindolo L. Operative profile, safety and functional outcomes after GreenLight laser prostate surgery: results from a 12 months follow-up multicenter Italian cohort analyses. Minerva Urol Nefrol. 2020;72(5):622-8. https://doi.org/10.23736/S0393-2249.20. 03597-3.

15. Fiori C, Checcucci E, Gilling P, Amparore D, Volpi G, De Cillis S, Aimar R, Sica M, Cattaneo G, Alleva G, Manfredi M, Porpiglia F; ESUT Lower Tract Group. All you need to know about "Aquablation" procedure for treatment of benign prostatic obstruction. Minerva Urol Nefrol. 2020;72(2):152-161. https:// doi.org/10.23736/S0393-2249.20.03654-1.

16. De Nunzio C, Tabatabaei S, Tubaro A. Ejaculation disorders in prostate surgery. Minerva Urol Nefrol. 2019;71(5):549-50. https://doi.org/10.23736/S0393-2249.19.03638-5 (PMID: 31646849).
17. Fuschi A, Al Salhi Y, Velotti G, Capone L, Martoccia A, Suraci PP, Scalzo S, Annino F, Khorrami S, Asimakopoulos A, Bozzini G, Falsaperla M, Carbone A, Pastore AL. Holmium laser enucleation of prostate versus minimally invasive simple prostatectomy for large volume $(\geq 120 \mathrm{ml})$ prostate glands: a prospective multicenter randomized study. Minerva Urol Nefrol. 2020 Nov 17. doi: https://doi.org/10.23736/S0393-2249. 20.04043-6. Epub ahead of print. PMID: 33200899.

18. Leonardo C, Lombardo R, Cindolo L, Antonelli A, Greco F, Porreca A, Veneziano D, Pastore A, Dalpiaz O, Ceruti C, Verze P, Borghesi M, Schiavina R, Falabella R, Minervini A; AGILE Group. What is the standard surgical approach to large volume BPE? Systematic review of existing randomized clinical trials. Minerva Urol Nefrol. 2020;72(1):22-29. doi: https:// doi.org/10.23736/S0393-2249.19.03589-6. Epub 2019 Oct 10. PMID: 31619035.

19. Manfredi M, Fiori C, Peretti D, Piramide F, Checcucci E, Garrou D, Amparore D, De Luca S, Di Dio M, Scarpa RM, Porpiglia F. Laparoscopic simple prostatectomy: complications and functional results after five years of follow-up. Minerva Urol Nefrol. 2020;72(4):498-504. https://doi.org/10.23736/ S0393-2249.19.03526-4.

20. Autorino R, Zargar H, Mariano MB, Sanchez-Salas R, Sotelo RJ, Chlosta PL, Castillo O, Matei DV, Celia A, Koc G, Vora A, Aron M, Parsons JK, Pini G, Jensen JC, Sutherland D, Cathelineau X, Nuñez Bragayrac LA, Varkarakis IM, Amparore D, Ferro M, Gallo G, Volpe A, Vuruskan H, Bandi G, Hwang J, Nething J, Muruve N, Chopra S, Patel ND, Derweesh I, Champ Weeks D, Spier R, Kowalczyk K, Lynch J, Harbin A, Verghese M, Samavedi S, Molina WR, Dias E, Ahallal Y, Laydner H, Cherullo E, De Cobelli O, Thiel DD, Lagerkvist M, Haber GP, Kaouk J, Kim FJ, Lima E, Patel V, White W, Mottrie A, Porpiglia F. Perioperative outcomes of robotic and laparoscopic simple prostatectomy: a European-American multiinstitutional analysis. Eur Urol. 2015;68(1):86-94. https://doi. org/10.1016/j.eururo.2014.11.044 (Epub 2014 Dec 4).

21. Porpiglia F, Fiori C, Bertolo R, Garrou D, Cattaneo G, Amparore D. Temporary implantable nitinol device (TIND): a novel, minimally invasive treatment for relief of lower urinary tract symptoms (LUTS) related to benign prostatic hyperplasia (BPH): feasibility, safety and functional results at 1 year of follow-up. BJU Int. 2015;116(2):278-87.

22. Porpiglia F, Fiori C, Bertolo R, Giordano A, Checcucci E, Garrou D, Cattaneo G, De Luca S, Amparore D. 3-Year follow-up of temporary implantable nitinol device implantation for the treatment of benign prostatic obstruction. BJU Int. 2018;122(1):106-12. https://doi.org/10.1111/bju.14141.

23. Porpiglia F, Fiori C, Amparore D, Kadner G, Manit A, Valerio M, Nicolaas L, Ho BSH, Alonso S, Schulman C, Barber N. Second-generation of temporary implantable nitinol device for the relief of lower urinary tract symptoms due to benign prostatic hyperplasia: results of a prospective, multicentre study at 1 year of follow-up. BJU Int. 2019;123(6):1061-9. https:// doi.org/10.1111/bju.14608.

24. Kadner G, Valerio M, Giannakis I, Manit A, Lumen N, Ho BSH, Alonso S, Schulman C, Barber N, Amparore D, Porpiglia F. Second generation of temporary implantable nitinol device (iTind) in men with LUTS: 2 year results of the MT02-study. World J Urol. 2020;38(12):3235-44. https://doi.org/ 10.1007/s00345-020-03140-z.

25.• Amparore D, Fiori C, Valerio M, Schulman C, Giannakis I, De Cillis S, Kadner G, Porpiglia F. 3-Year results following treatment with the second generation of the temporary implantable nitinol device in men with LUTS secondary to benign prostatic obstruction. Prostate Cancer Prostatic Dis. 2020. https://doi. 
org/10.1038/s41391-020-00281-5. (Paper with the longest follow-up reported after iTIND implantation)

26. De Nunzio C, Cantiello F, Fiori C, Crocerossa F, Tognoni P, Amparore D, Baldassarri V, Elbers JR, Sancha FG, Porpiglia F. Urinary and sexual function after treatment with temporary implantable nitinol device (iTind) in men with LUTS: 6-month interim results of the MT-06-study. World J Urol. 2020. https:// doi.org/10.1007/s00345-020-03418-2.

27.• Chughtai B, Elterman D, Shore N, Gittleman M, Motola J, Pike S, Hermann C, Terrens W, Kohan A, Gonzalez RR, Katz A, Schiff J, Goldfischer E, Grunberger I, Tu LM, Alshak MN, Kaminetzky J. The iTind temporarily implanted nitinol device for the treatment of lower urinary tract symptoms secondary to benign prostatic hyperplasia: a multicenter, randomized, controlled trial. Urology. 2020:S0090-4295(20)31520-X. doi: https://doi.org/10.1016/j.urology.2020.12.022. The only RCT currently available in literature compairing iTIND implantation versus sham procedure for treatment of BPH related LUTS.

28. Madersbacher S, Lackner J, Brössner C, et al. Reoperation, myocardial infarction and mortality after transurethral and open prostatectomy: a nation-wide, long-term analysis of 23,123 cases. Eur Urol. 2005;47(4):499-504. https://doi.org/10.1016/j.eururo. 2004.12.010.

Publisher's Note Springer Nature remains neutral with regard to jurisdictional claims in published maps and institutional affiliations. 